\title{
Produtividade da soja e bioindicadores do solo em função da inoculação de Bradyrhizobium e Azospirillum em sucessão de cultivos
}

\author{
Renato Albuquerque da $\mathrm{Luz}^{1}$, Ricardo Fachinelli ${ }^{1}$, Hadassa Kathyuci Antunes Abreu ${ }^{1}$, Priscila Akemi Makino ${ }^{1}$, \\ Gessí Ceccon ${ }^{2}$ \\ ${ }^{1}$ Universidade Federal da Grande Dourados - UFGD, Pós-graduação em Agronomia, Dourados, MS. ${ }^{2}$ Embrapa \\ Agropecuária Oeste, Dourados, MS. E-mail: renatoalbuquerqueluz@gmail.com
}

\begin{abstract}
Resumo
Com o aumento da demanda mundial por soja, se faz necessário utilizar técnicas alternativas para aumentar a produção da cultura de forma sustentável. A fixação biológica de nitrogênio - FBN realizada por meio de bactérias diazotróficas é considerado uma fonte eficaz e econômica para fornecimento de $\mathrm{N}$ para a soja. Desta forma, o objetivo deste trabalho foi avaliar a produtividade da soja e bioindicadores do solo em função da inoculação de Bradyrhizobium japonicum isolado e a coinoculação com Azospirillum brasilense em sucessão de culturas de outono-inverno. O estudo foi conduzido na área experimental da Embrapa Agropecuária Oeste, em Dourados, MS, na safra 2016/2017. O delineamento experimental foi em blocos casualizados em parcelas subdivididas com três repetições. Nas parcelas foram alocados os quatros cultivos de outono-inverno (milho solteiro, milho consorciado com Brachiaria ruziziensis, feijão-caupi solteiro e $B$. ruziziensis solteira), e nas subparcelas a inoculação via sementes: sem inoculação (testemunha); inoculação com Bradyrhizobium japonicum e coinoculação de B. japonicum + Azospirillum brasilense. A inoculação não foi significativa para nenhuma das variáveis mensuradas assim como a interação da inoculação $x$ culturas de outono-inverno. Os cultivos de outono-inverno influenciaram na produtividade dos grãos, na qual, a soja cultivada em sucessão ao milho consorciado e feijão-caupi obtiveram destaque em suas médias. O carbono da biomassa, quociente metabólico e microbiano do solo foram influenciados pelos cultivos, sendo o maior valor de biomassa microbiana encontrado em sucessão ao milho consorciado, em relação ao feijão-caupi, B. ruziziensis e milho solteiro. A atividade da enzima fosfatase ácida não foi influenciada por nenhum fator estudado. $\mathrm{O}$ uso de culturas de outono-inverno contribui para o desempenho da soja em sucessão, e contribuem para aumento da biomassa microbiana do solo.
\end{abstract}

Palavras-chave: coinoculação; microbiologia do solo; rotação de culturas; Glycine max L.

Soybean productivity and soil bioindicators in the function of Bradyrhizobium and Azospirillum inoculation in succession of crops

\begin{abstract}
As world demand for soybeans increases, it is necessary to use alternative techniques to increase the production of the crop in a sustainable way. Biological nitrogen fixation - BNF performed by diazotrophic bacteria is considered an efficient and economical source for $\mathrm{N}$ supply to the soybean. This study aimed to evaluate soybean productivity and soil bioindicators as a function of the inoculation of Bradyrhizobium japonicum isolated and the co-inoculation with Azospirillum brasilense in succession of autumn-winter crops. The experiment was carried out in the experimental area of Embrapa Western Agriculture, in Dourados, MS, in the 2016/2017 harvest season. The experimental design was in randomized blocks in subdivided plots with three replicates. In the plots were allocated the four autumn-winter crops (single corn, corn intercropped with Brachiaria ruziziensis, single cowpea and single B. ruziziensis), and in the subplots inoculation via seeds: without inoculation (control); inoculation with B. japonicum and coinoculation of $B$. japonicum $+A$. brasilense. No significant effect of inoculation methods was observed on the studied variables as well as an interaction of inoculation vs. autumn-winter crops. The autumn-winter crops influence the grain yield, which the soybeans cultivated in succession to intercropping maize and cowpea achieved better averages. The microbial biomass carbon, metabolic and microbial quotients were
\end{abstract}


influenced by the crops, being the highest value of microbial biomass carbon found in succession to intercropped corn, in relation to cowpea, B. ruziziensis and single maize. The activity of the acid phosphatase enzyme was not influenced by any factor studied. The use of autumn-winter crops contributes to the performance of soybeans in succession and contribute to the increase of soil microbial biomass.

Key words: co-inoculation; soil microbiology; crop rotation; Glycine max L.

\section{Introdução}

A cultura da soja (Glycine max (L.) Merrill) é uma oleaginosa de grande importância mundial, sendo o Brasil o segundo maior produtor da oleaginosa, com área cultivada estimada de 35 milhões de hectares (CONAB, 2018). Ao mesmo modo, a demanda pelos grãos de soja e seus subprodutos vem crescendo exponencialmente nas últimas décadas pelo consumo no mercado alimentício e industrial (CASTANHEIRA et al., 2015; HENCHION et al., 2014). Sendo assim, é necessária a utilização de tecnologias alternativas visando aumentar a produtividade da cultura com baixo custo, por meio de fontes alternativas de nutrição vegetal, e práticas conservacionistas do solo.

Como fonte nutricional alternativa para a cultura da soja, destaca-se a utilização de inoculação nas sementes de bactérias diazotróficas principalmente do gênero Bradyrhizobium spp., técnica difundida mundialmente, é responsável pelo fornecimento total de nitrogênio $(\mathrm{N})$ para a cultura por meio da fixação biológica de nitrogênio (FBN). Estas bactérias são responsáveis por romper as ligações e transforma-lo em $\mathrm{N}$ amônio nos nódulos, sendo posteriormente transportados como íon amônio dentro das plantas (HUNGRIA, 2013). Igualmente, as bactérias do gênero Azospirillum spp. possuem elevado potencial agronômico, pois além da FBN contribuem para a produção fito hormônios, tais como auxinas, citocininas, giberilinas e etileno, auxiliando no desenvolvimento e produtividade das culturas (ARAUJO, 2008).

Desta forma, nos últimos anos algumas técnicas para potencializar o efeito dos gêneros Bradyrhizobium spp. e Azospirillum spp. vem sendo estudados e desenvolvidos, como solução, a coinoculação ou inoculação mista aparece como alternativa. esta técnica consiste na combinação desses diferentes microrganismos, os quais produzem efeitos múltiplos de sinergismo na planta, e com a capacidade de superar os resultados de produtividade quando comparados aos efeitos isoladamente (HUNGRIA, 2013).

Assim como a FBN, a rotação de culturas em sistema plantio direto (SPD) é uma alternativa de manejo do solo que tem contribuído para aumentar a produtividade de grãos das culturas (OLIVEIRA et al., 2013). Entretanto, para a obtenção de um sistema eficaz em algumas regiões o fator cobertura vegetal acumulada pelas culturas de coberturas e/ou pastagem é fundamental para proporcionar ambiente favorável para solo, com manutenção dos atributos químicos, físicos e microbiológicos e consequentemente maior produtividade das culturas (COSTA et al., 2015; SANTOS et al., 2011).

Com relação a importância da biomassa microbiana para a qualidade dos ecossistemas agrícolas, Kaschuck et al. (2011) destacam que este parâmetro possui uma influência direta dos manejos culturais sobre os microrganismos e na ciclagem dos nutrientes no solo, sobretudo de nitrogênio, fósforo e enxofre no solo.

Objetivou-se com este trabalho, avaliar o efeito da inoculação de Bradyrhizobium japonicum e Azospirillum brasilense nas sementes de soja cultivada após espécies de outonoinverno em sistema plantio direto sobre a produtividade da soja, e os bioindicadores microbiológicos do solo.

\section{Material e Métodos}

O experimento foi realizado na área experimental da Embrapa Agropecuária Oeste, localizado no município de Dourados-MS, coordenadas $22^{\circ} 13^{\prime}$ latitude Sul e $54^{\circ} 48^{\prime}$ longitude Oeste, aproximadamente $408 \mathrm{~m}$ de altitude. O solo é classificado como Latossolo Vermelho Distroférrico de textura muito argilosa (SANTOS et al., 2013). A análise química do solo na camada $0-0,20 \mathrm{~m}$ apresentou os seguintes resultados: $\mathrm{pH}\left(\mathrm{CaCl} 20,01 \mathrm{ml}^{-1}\right)=6,2 ; \mathrm{V}=79,3 \%$; M.O $\left(\mathrm{g} \mathrm{kg}^{-1}\right)=57,9 ; \mathrm{P}\left(\mathrm{mg} \mathrm{dm}^{-3}\right)=57,3 ; \mathrm{K}(\mathrm{cmolc}$ $\mathrm{dm}^{-3}$ ) = 1,0; Ca $\left(\mathrm{cmolc} \mathrm{dm}^{-3}\right)=6,5 ; \mathrm{Mg}$ (cmolc dm $\left.{ }^{3}\right)=2,8$ e Al $\left(\mathrm{cmolc} \mathrm{dm}^{-3}\right)=2,7$. E a analise 
granulométrica apresentou: Areia $\left(\mathrm{g} \mathrm{kg}^{-1}\right)=136$; Silte $\left(\mathrm{g} \mathrm{kg}^{-1}\right)=151$ e Argila $\left(\mathrm{g} \mathrm{kg}^{-1}\right)=713$.

- O clima da região é classificado como

Am (Tropical Monçônico), segundo a classificação de Köppen, com verões quentes e invernos secos, temperaturas máximas observadas nos meses de dezembro e janeiro e temperaturas mínimas entre maio e agosto, coincidindo com chuvas excedentes na primavera - verão e déficit hídrico no outono - inverno (FIETZ et al., 2013). Os dados de temperatura e precipitação foram obtidos na Estação meteorológica da Embrapa Agropecuária Oeste (Figura 1).

Figura 1. Precipitação, temperaturas máximas (TM) e mínimas (Tm) decendiais, no período de 07 de outubro de 2016 a 29 de janeiro de 2017 em Dourados, MS.

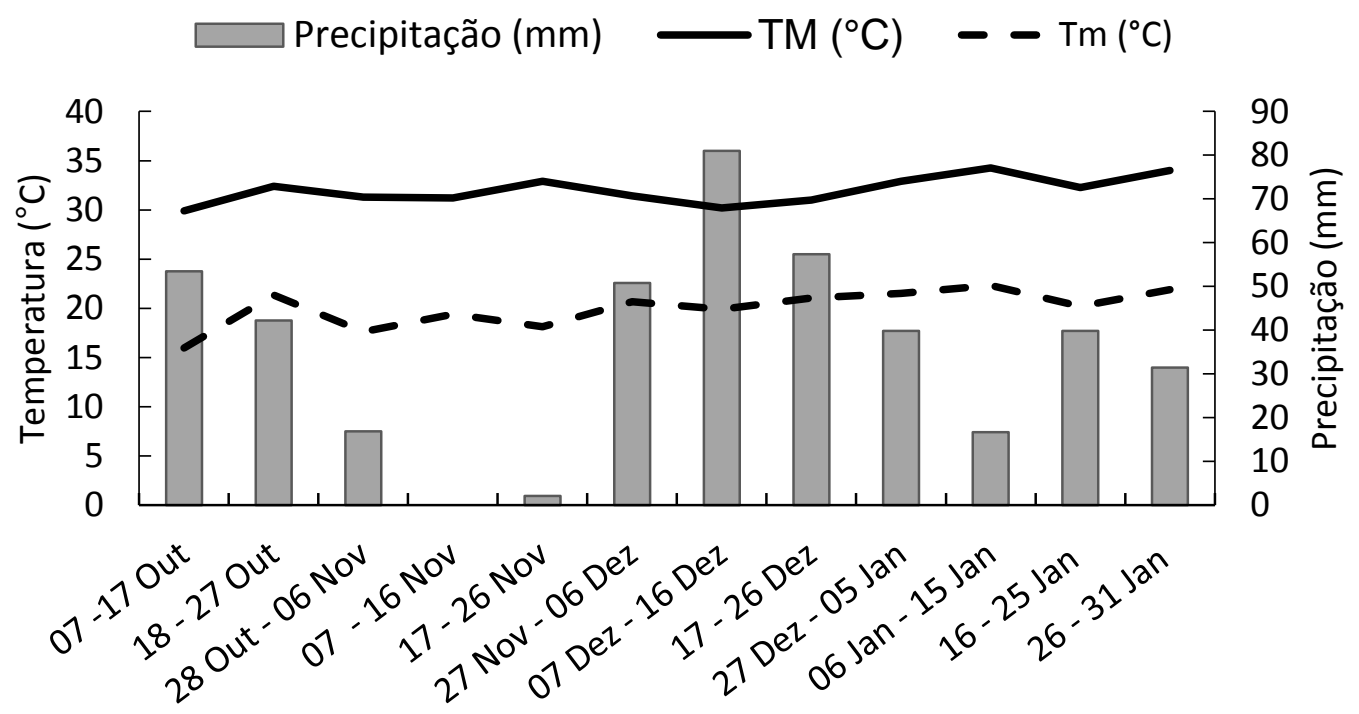

Fonte: Embrapa Agropecuária Oeste (2018).

A área experimental é manejada em plantio direto há 16 anos, num esquema de rotação de culturas há nove anos, sendo no outono-inverno cultivado feijão-caupi (Vigna unguiculata), milho safrinha solteiro, Brachiaria ruziziensis e consórcio de milho com $B$. ruziziensis, no verão é cultivada a soja. $O$ experimento foi realizado no ano agrícola 2016/17, sendo realizado a semeadura mecânica das culturas de outono-inverno em março de 2016, em parcelas de $10 \times 50 \mathrm{~m}$ com três repetições. A colheita das culturas do feijão-caupi e milho ocorrem em junho e julho, e o pastejo na braquiária solteira e do consorcio ocorreu até agosto. A dessecação das parcelas das culturas de outono-inverno foi realizada 30 dias antes da semeadura da soja com glifosato potássico, na dose de $2 \mathrm{~kg} \mathrm{ha}^{-1}$ de equivalente ácido, para supressão de plantas daninhas e braquiária dos cultivos de outono-inverno. Um dia antes da semeadura da soja foi coletado os resíduos presentes na superfície do solo, secados em estufa a $60^{\circ} \mathrm{C}$ até peso constante e depois convertidos em $\mathrm{kg} \mathrm{ha}^{-1}$, sendo rendimento de massa seca das culturas de outono inverno: milho solteiro $=7.072 \mathrm{~kg} \mathrm{ha}^{-1}$; milho consorciado $=$ $7.786 \mathrm{~kg} \mathrm{ha}^{-1}$; feijão-caupi $=2.841 \mathrm{~kg} \mathrm{ha}^{-1} ; B$. ruziziensis solteira $=6.695 \mathrm{~kg} \mathrm{ha}^{-1}$.

O delineamento experimental utilizado foi em blocos casualizados em parcelas subdivididas com três repetições. Nas parcelas foram alocados os quatros cultivos de outonoinverno (milho solteiro, milho consorciado com braquiária, feijão-caupi solteiro e braquiária solteira) com dimensões de $10 \times 12,5 \mathrm{~m}$ cada parcela, e nas subparcelas os métodos de inoculação via semente: 1) sem inoculação (testemunha), 2) inoculação com Bradyrhizobium japonicum na dose de $100 \mathrm{~g} / 50 \mathrm{~kg}$ de semente da estirpe CPAC 15 (SEMIA 5079) e estirpe CPAC 7 (SEMIA 5080), contendo $7 \times 10^{-9}$ unidades formadoras de colônia (UFC $\mathrm{g}^{-1}$ do produto comercial) de inoculante turfoso; 3) inoculação com Bradyrhizobium japonicum e Azospirillum brasilense, na dose de $120 \mathrm{ml} / 50 \mathrm{~kg}$ de sementes (estirpes Ab-V5 e Ab-V6) com garantias de $2 \times 10^{-8}$ UFC $\mathrm{mL}^{-1}$, dimensões de $3,30 \times 10 \mathrm{~m}$ cada subparcela. Na safra de soja 2015/2016, foi realizada a inoculação de $B$. japonicum, e a co- 
inoculação com A. brasilense na cultura da soja na mesma área.

A semeadura da cultivar de soja BRS 1003 IPRO foi realizada no dia 07 de outubro de 2016, em plantio direto, com regulagem de $200 \mathrm{~kg} \mathrm{ha}^{-1}$ de fertilizante NPK, formula 00-20-20, e espaçamento de $0,5 \mathrm{~m}$ entre linhas, com população de 280 mil plantas por hectare e semeadas a $5 \mathrm{~cm}$ de profundidade. $\mathrm{Na}$ semeadura a sequência obedeceu a seguinte ordem: tratamento sem inoculante, seguido do tratamento somente com B. japonicum, e por último o tratamento com B. japonicum com $A$. brasilense, com $O$ objetivo de evitar contaminação entre os tratamentos utilizados.

$\mathrm{Na}$ primeira quinzena de novembro amostras de solos na camada 0 a $10 \mathrm{~cm}$ foram coletas das parcelas, cada amostra foi composta por quatro pontos de coleta. O material foi armazenado em câmara fria com temperatura média de $\pm 7^{\circ} \mathrm{C}$ até 0 momento das análises. As análises biológicas foram realizadas no laboratório de solos da Embrapa Agropecuária Oeste, localizado em Dourados (MS). A análise do carbono da biomassa microbiana do solo (C-BMS) foi realizada pelo método da fumigação-extração, adotando-se fator de correção para eficiência de extração ( $k_{\text {ec }}$ ) igual a 0,33 (VANCE et al. 1987); a respiração basal $\left(\mathrm{C}^{-} \mathrm{CO}_{2}\right)$ foi obtida pelo método da respirometria, evolução de $\mathrm{CO}_{2}$ (JENKINSON; POWLSON, 1976); o quociente microbiano ( $q \mathrm{MIC})$, expresso em percentagem, foi calculado pela fórmula (C-BMS/C org) x 100; e o quociente metabólico $\left(q \mathrm{CO}_{2}\right)$ foi obtido pela divisão dos valores da respiração basal pelo do carbono microbiano $\left(\mu \mathrm{CO}_{2} / \mu \mathrm{g} \quad \mathrm{C}-\mathrm{BMS} \mathrm{h}^{-1}\right)$. A análise química para a determinação do carbono orgânico total (C-orgânico total) do solo foi determinada de acordo com metodologia descrita por Claessen (1997).
Na primeira quinzena de janeiro de 2017, foi realizado coletas amostras de solos para análise da enzima fosfatase ácida, foi amostrado na profundidade de $0-10 \mathrm{~cm}$, em que cada amostra foi composta por quatro pontos de coleta. A atividade da fosfatase ácida foi determinada segundo a metodologias proposta por Tabatabai e Bremner, (1969), sendo os valores expressos em $\mathrm{mg} p$-nitrofenol $\mathrm{g}^{-1}$ solo $\mathrm{h}^{-1}$.

No estádio de maturidade fisiológica da soja, foram coletadas todas as plantas nas duas linhas centrais da parcela com cinco metros de comprimento para avaliação de produtividade de grãos, posteriormente as amostras foram processadas e os resultados extrapoladas para $\mathrm{kg}$ $\mathrm{ha}^{-1}$.

Os dados foram submetidos à análise de variância, quando significativo foi realizado o teste de comparação de médias Tukey $(p<0,05)$ de probabilidade, utilizando-se o programa estatístico Sisvar (FERREIRA, 2014).

\section{Resultado e Discussões}

Para os atributos microbiológicos analisados não foi observado efeito significativo da inoculação para nenhuma das variáveis, assim como não houve interação significativa entre os fatores inoculação $x$ culturas de outono-inverno. Observou-se efeito das culturas de outono inverno sobre o carbono da biomassa microbiana (C-BMS), quociente metabólico $\left(q \mathrm{CO}_{2}\right)$, quociente microbiano ( $q \mathrm{MIC})$ e produtividade de grãos, contudo para a respiração basal $\left(\mathrm{C}-\mathrm{CO}_{2}\right)$ e atividade enzimática da fosfatase ácida ( $p$ nitrofenol) não houve significância para este fator (Tabela 1). 
Tabela 1. Resumo da análise de variância de carbono da biomassa microbiana (C-BMS), respiração basal (C$\mathrm{CO}_{2}$ ), quociente metabólico $\left(\mathrm{qCO} \mathrm{CO}_{2}\right.$ ), quociente microbiano ( $q \mathrm{MIC}$ ), e atividade da fosfatase acida (PNF.) do solo, e produtividade de grãos em função de métodos de inoculação e sistemas de sucessão de culturas de outono-inverno, em Dourados-MS, 2018.

\begin{tabular}{cccccccc}
\hline \multirow{2}{*}{ Fatores de Variação } & G.L. & \multicolumn{5}{c}{ Quadrado Médio } \\
\cline { 3 - 7 } & & C-BMS & ${\mathrm{C}-\mathrm{CO}_{2}}$ & $q \mathrm{CO}_{2}$ & $q \mathrm{MIC}$ & $\mathrm{PNF}$ & Produtividade \\
\hline Blocos & 2 & 1068827,02 & 163,41 & 6757,70 & 2,06 & 22575,20 & 426600 \\
Culturas & 2 & $17835,75^{*}$ & $6,53^{\text {ns }}$ & $680,79^{*}$ & $0,38^{*}$ & $18584,00^{\text {ns }}$ & $1085143^{*}$ \\
Resíduo (a) & 6 & 4260,72 & 37,69 & 275,38 & 0,07 & 6688,27 & 21640 \\
CV a (\%) & - & 28,56 & 36,91 & 43,40 & 22,24 & 14,70 & 17,45 \\
Inoculação & 3 & $1063,66^{\text {ns }}$ & $81,86^{\text {ns }}$ & $127,24^{\text {ns }}$ & $0,06^{\text {ns }}$ & $1526,37^{\text {ns }}$ & $46271^{\text {ns }}$ \\
Culturas x Inoculação & 6 & $4260,72^{\text {ns }}$ & $37,67^{\text {ns }}$ & $275,38^{\text {ns }}$ & $0,07^{\text {ns }}$ & $6687,96^{\text {ns }}$ & $65356^{\text {ns }}$ \\
Resíduo (b) & 16 & 335,21 & 30,35 & 137,18 & 0,09 & 19485,30 & 66871 \\
CV b (\%) & - & 25,27 & 33,12 & 30,63 & 24,89 & 25,10 & 9,70 \\
\hline
\end{tabular}

G.L. = Graus de Liberdade; ${ }^{*}=$ significativo a $(p<0,05) ; n s=$ não significativo; C.V.=coeficiente de variação.

O consórcio de milho com braquiária proporcionou maior média de C-BMS em relação ao cultivo de milho solteiro, na ordem de 63,6\%, no entanto, não houve diferença estatística nos valores desta variável para as culturas de feijãocaupi e $B$. ruziziensis, que por sua vez, não variaram estatisticamente do milho solteiro (Tabela 2). Fatores como diversidade de raízes, quantidade de resíduos vegetais, assim como, a qualidade destes resíduos (relação $\mathrm{C} / \mathrm{N}$ ) favorecem a maiores teores de biomassa microbiana (LOURENTE et al., 2011; SOARES, 2017). A inoculação não apresentou diferença significativa para o C-BMS, no qual, os valores variaram de 221,88 a $239,29 \mu \mathrm{g} \mathrm{C} \mathrm{g}^{-1}$ solo seco entre os tratamentos.

$\mathrm{O}$ acúmulo de $\mathrm{C}$ no solo devido ao cultivo de diferentes espécies, leguminosas e gramíneas, com a entrada de diferentes resíduos e sistemas radiculares favorecem a manutenção de C-BMS nesses sistemas. A soja em sucessão ao milho safrinha solteiro é um sistema que não causa diversidade radicular desejável, sendo possível observar esse efeito na variação da C-BMS em relação a um sistema mais complexo, como o milho consorciado (outono-inverno) / soja (primavera-verão).

A diversificação de culturas em SPD influencia os valores de C-BMS, uma vez que, a variação de resíduos produzidos pelas culturas fornece $\mathrm{C}$ suficiente para a aumento da matéria orgânica do solo, principalmente nas camadas superficiais, assim a microbiota se torna mais abundante. Navroski et al., (2018) avaliando atributos microbiológicos em diversas camadas de Latossolo Vermelho distroférrico cultivado em sistema plantio direto (SPD) em comparação ao cultivo convencional, reportaram que os diferentes sistemas de coberturas influenciam os atributos microbiológicos $\mathrm{C}-\mathrm{BMS}, \mathrm{C}-\mathrm{CO}_{2}, q \mathrm{CO}_{2}$ e o qMIC, principalmente nas camadas mais subsuperficiais $(0-10 \mathrm{~cm})$.

De acordo com Lopes et al., (2018), os valores de C-BMS na camada de $0-20 \mathrm{~cm}$ (para Latossolo argilosos no Cerrado em SPD) obtidos no presente trabalho foram baixos $(<245 \mathrm{mg} \mathrm{kg}$ $\left.{ }^{1}\right)$ em sucessão de milho solteiro, feijão-caupi solteiro e $B$. ruziziensis solteira, e moderado (245$440 \mathrm{mg} \mathrm{kg}^{-1}$ ) em sucessão ao milho consorciado. 
Tabela 2. Valores médios de carbono da biomassa microbiana (C-BMS), quociente metabólico $\left(\mathrm{qCO}_{2}\right)$, quociente microbiano (qMIC) do solo em sucessão de cultivos de outono-inverno, em Dourados - MS, 2018.

\begin{tabular}{|c|c|c|c|}
\hline & C-BMS & $q \mathrm{CO}_{2}$ & $q \mathrm{MIC}$ \\
\hline Sistema de sucessão de culturas & $\begin{array}{l}\mu \mathrm{g} \mathrm{C} \mathrm{g}^{-1} \\
\text { solo seco }\end{array}$ & $\begin{array}{c}\mu \mathrm{g} \mathrm{C}-\mathrm{CO}_{2} \mu \mathrm{g}^{-1} \\
\mathrm{C}^{-B M S ~ h^{-1}}\end{array}$ & $\%$ \\
\hline Milho solteiro & $167,90 \mathrm{~b}$ & $50,99 a$ & $0,92 \mathrm{~b}$ \\
\hline $\begin{array}{l}\text { Milho consorciado } \\
\text { com B. ruziziensis }\end{array}$ & 274,64 a & $34,86 a b$ & $1,39 a$ \\
\hline Feijão-caupi solteiro & $231,31 a b$ & $31,45 b$ & $1,34 \mathrm{a}$ \\
\hline B. ruziziensis solteira & $240,20 a b$ & $35,37 \mathrm{ab}$ & $1,24 a b$ \\
\hline Média & 228,51 & 38,23 & 1,22 \\
\hline C.V (\%) & 28,56 & 43,40 & 22,24 \\
\hline
\end{tabular}

Médias seguidas por letras iguais, na coluna, não diferem entre si pelo teste de Tukey, a 5\% de probabilidade.

A $\mathrm{C}_{-} \mathrm{CO}_{2}$ não apresentou diferença estatística para o fator sistemas de sucessão de culturas, e as médias variaram entre 15,65 e $17,46 \mathrm{mg} \mathrm{C} \mathrm{kg}^{-1}$ solo dia ${ }^{-1}$ para milho consorciado, milho solteiro, feijão-caupi solteiro e $B$. ruziziensis solteira, assim como, o fator inoculação que variou 13,74 a $18,81 \mathrm{mg} \mathrm{C} \mathrm{kg}^{-1}$ solo dia ${ }^{-1}$, sendo classificados como teores baixos segundo Lopes et. al. (2013). As baixas precipitações pluviométricas e altas temperaturas na área, antes das coletas das amostras contribuíram para a falta de significância, pois a quantidade de $\mathrm{CO}_{2}$ liberado pela respiração é influenciado por diferentes fatores, tal como umidade, temperatura e disponibilidade de nutrientes no solo, (REIS JUNIOR; MENDES, 2007).

$\mathrm{O}$ quociente metabólico $\left(\mathrm{qCO}_{2}\right)$ é o indicador da eficiência dos microrganismos no uso do substrato de diferentes sistemas de cultivos, assim observou-se uma variação entre os sistemas de cultivos, apresentando o melhor resultado na área que foi cultivado feijão-caupi solteiro, mas não diferiu estatisticamente com os tratamentos de milho consorciado e $B$. ruziziensis solteira (Tabela 2). O milho solteiro apresentou um maior índice de $q \mathrm{CO}_{2}$ sendo $62,18 \%$ em relação ao menor, o feijão-caupi. O feijão-caupi possui uma relação carbono nitrogênio $(C / N)$ mais baixa que o milho solteiro, desta maneira a rápida disponibilização de carbono orgânico no solo contribuiu para o aumento da atividade microbiana (NAVROSKI et al., 2018). Médias elevadas indicam que a taxa de respiração desse sistema não está sendo eficiente. Indicando que a comunidade microbiológica está sofrendo algum tipo de estresse metabólico, ou ainda uma colônia em estágio inicial de desenvolvimento (ADERSON; DOMSCH 1990). As médias para a inoculação variaram entre 34,53 e $39,52 \mu \mathrm{g} C-\mathrm{CO}_{2}$ $\mu \mathrm{g}^{-1} \mathrm{C}-\mathrm{BMS} \mathrm{h}^{-1}$ entre os tratamentos de inoculação na semente.

Para o quociente microbiano ( $q \mathrm{MIC})$, a inoculação apresentou resultados variando entre $1,20 \%$ a $1,25 \%$. Os maiores qMIC foram encontrados nos tratamentos de milho consorciado e feijão-caupi, em relação ao milho solteiro (Tabela 2), e $B$. ruziziensis não diferiu entre os demais tratamentos. $\mathrm{O}$ valor do $q \mathrm{MIC}$ do milho foi abaixo de $1 \%(0,92 \%)$, indicando alguma limitação na atividade microbiana do solo, limitação causada por fatores edafoclimáticos (LEITE et al., 2013). Segundo Mercante (2001), a relação entre carbono microbiano e carbono orgânico (qMIC) pode apontar uma disponibilidade da matéria orgânica para os microrganismos, e números maiores deste quociente indicam aumento da sua dinâmica no solo (SAMPAIO et al. 2008).

A atividade enzimática não diferiu entre os tratamentos, obtendo média de 556,21 mg pnitrofenol. De acordo com Lopes et al., (2018), o nível da enzima fosfatase para os solos do Cerrado é considerado baixo $1<660 \mathrm{mg} \mathrm{p}$ nitrofenol), e a instabilidade climática ocorrida durante o experimento pode ter influenciado nos resultados obtidos. Os resultados obtidos neste trabalho corroboram com os obtidos por Mazzuchelli et al., (2017), no qual ao avaliarem a atividade enzimática após o cultivo de diversas espécies de outono-inverno (milho, milheto, $B$. brizantha, sorgo, girassol e guandu) não constataram influência das culturas sobre seu teor.

O clima durante a condução do experimento foi marcado por um regime pluviométrico abaixo da média e temperaturas elevadas, característica da região, que interferiram na atividade microbiana do solo. Portanto, fica evidente neste trabalho que a 
utilização de um sistema de produção agrícola baseado em diversidade de culturas pode diminuir efeitos climáticos desfavoráveis. $\mathrm{Na}$ presente situação, o consorcio milho com braquiária, feijão-caupi solteiro e $B$. ruziziensis solteira, mesmo produzindo menos cobertura, cultivados no outono inverno proporcionaram melhores condições para o desenvolvimento da população de microrganismos em comparação a sucessão soja e milho solteiro.

A utilização da coinoculação de $B$. japonicum com $A$. brasilense na soja não apresentou significância na produtividade quando comparado aos tratamentos com inoculação de $B$. japonicum e testemunha, sendo as médias de produtividade de $2.619 \mathrm{~kg} \mathrm{ha}^{-1}$, $2.642 \mathrm{~kg} \mathrm{ha}^{-1}$ e $2.736 \mathrm{~kg} \mathrm{ha}^{-1}$ para a testemunha, inoculação com B. japonicum e coinoculação, respectivamente. Os benefícios da coinoculação de Bradyrhizobium spp. com Azospirillum spp. em leguminosas são controversos. Hungria, (2013) avaliando o efeito da coinoculação na cultura da soja, não observou diferença significativa entre os tratamentos com a testemunha, enquanto, Hungria et al., (2015) observaram efeitos positivos da associação das bactérias. A não ocorrência de diferença nos resultados deve-se a fatores intrínsecos de condições ambientais do solo e de cultivares que respondem a bactérias associativas (BULEGON et al., 2016).

Mesmo na produtividade de grãos não foi observado diferença estatística significativa entre os tratamentos, mas as médias de produtividade apresentaram diferença numérica nos seus valores, de tal modo, que a coinoculação de bactérias $F B N$ e promotora de crescimento vegetal aumentou o rendimento de grãos em 117 $\mathrm{kg} \mathrm{ha}{ }^{-1}(4,48 \%)$ em relação a testemunha, evidenciando a possibilidade de influência econômica devido ao baixo valor de custo de tratamento. As bactérias podem fornecer quantidades suficientes de $\mathrm{N}$ para suprir as necessidades da cultura, sendo dispensando o uso de parte da adubação nitrogenada, assim gerando economia para o produtor (BRACCINI et al., 2016).

A produtividade da soja em sucessão de culturas de outono-inverno apresentou diferença estatística, em que, o milho consorciado e o feijão-caupi solteiro apresentaram médias $25 \%$ superiores em relação a $B$. ruziziensis solteira, mas não diferindo do milho solteiro (tabela 3 ).

Fatores como o clima e fertilidade natural do solo contribuíram para os resultados encontrados, uma vez que, durante os meses de outubro e janeiro da safra 2016/2017, período entre a germinação e colheita da soja, a precipitação pluviométrica registrada no local do experimento foi de $438 \mathrm{~mm}$, portanto no mínimo da exigência da cultura da soja, que possui exigência hídrica entre 450 a $850 \mathrm{~mm}$ para produção de biomassa e grãos (CARVALHO et al., 2013).

Tabela 3. Produtividade da soja em sucessão de culturas de outono-inverno, em Dourados - MS, 2018.

\begin{tabular}{cc}
\hline Sistema de sucessão de culturas & Produtividade de grãos \\
\cline { 2 - 2 } & $\mathrm{kg} \mathrm{ha}^{-1}$ \\
\hline Milho solteiro & $2.599 \mathrm{ab}$ \\
Milho consorciado & $2.934 \mathrm{a}$ \\
com B. ruziziensis & $2.928 \mathrm{a}$ \\
Feijão-caupi solteiro & $2.200 \mathrm{~b}$ \\
B. ruziziensis solteira & 2.665 \\
\hline Média & 9,70 \\
\hline C.V (\%)
\end{tabular}

Médias seguidas por letras iguais, na coluna, não diferem entre si pelo teste de Tukey, a 5\% de probabilidade.

Os resíduos vegetais das culturas antecessoras proporcionaram um microclima menos severo para a cultura, pois quando a cultura está sobre algum estresse em uma de suas fases importantes de desenvolvimento há tendência de ocorrer redução de altura, e diminuição de biomassa, e até abortamentos de flores e vagens (GAVA et al., 2015). Os teores de $\mathrm{pH}$, micro e macronutrientes, saturação de bases e matéria orgânica do solo da área onde o experimento foi conduzido encontram-se elevados. $\mathrm{Na}$ implantação das culturas de outono-inverno, os cultivos de milho solteiro e consorciado receberam adubação, enquanto, as demais culturas foram cultivadas sem a adição de fertilizantes. Esse fornecimento extra para os sistemas pode ter disponibilizados teores maiores para a cultura da soja. 
O bom desempenho da soja em sucessão ao feijão-caupi pode ser atribuído a rápida mineralização da matéria orgânica e posteriormente disponibilização dos nutrientes, aliado à capacidade de realizar fixação biológica de nitrogênio atmosférico ao solo, torna-se uma cultura com grande potencial agronômicos para usar em rotação de culturas (FREIRE FILHO et al., 2005). Essa liberação de nutrientes, principalmente de $\mathrm{N}$ da FBN, contribuiu para a alta produtividade da soja em sucessão. Oliveira et al. (2013), obtiveram maior produtividade de grão de soja em sucessão a feijão do que braquiária, resultado que corrobora com o encontrado neste trabalho. Desta maneira, a adição de feijão para sistemas de rotação de cultura pode contribuir para o incremento de nitrogênio, estimulando o desenvolvimento inicial de culturas que necessitam de um aporte no início.

\section{Conclusões}

A aplicação das bactérias de $B$. japonicum e $A$. brasilense na semente de soja não interferiu nos atributos microbiológicos do solo e produtividade de grãos da soja. A utilização de diferentes culturas no outono-inverno proporciona uma melhor biomassa microbiana em relação a sucessão de cultivo soja/milho solteiro. A soja em sucessão ao milho consorciado com $B$. ruziziensis e feijão-caupi apresentaram maiores produtividade de grãos comparada a $B$. ruziziensis.

\section{Referências}

ARAUJO, S. C. Realidade e perspectivas para o uso de Azoapirillum na cultura do milho. Revista Informações Agronômicas, n. 122, p. 4-6, 2008.

BRACCINI, A. L.; MARIUCCI, E. G. G.; SUZUKAWA, K. A.; SILVA LIMA, L.H.; PICCININ, G. G. Coinoculação e modos de aplicação de Bradyrhizobium japonicum e Azospirillum brasilense e adubação nitrogenada na nodulação das plantas e rendimento da cultura da soja. Scientia Agraria Paranaensis, v. 15, n. 1, p. 27-35, $2016 . \quad \quad$ http://dx.doi.org/10.18188/19831471/sap.v15n1p27-35.

BULEGON, L. G., L. RAMPIM, J. KLEIN, D. KESTRING, V. F. GUIMARÃES, A. G. BATTISTUS, E A. M. INAGAKI. Componentes de produção e produtividade da cultura da soja submetida à inoculação de Bradyrhizobium e Azospirillum. Terra Latinoamericana, v. 34, p. 169-176, 2016.

CARVALHO, I. R.; KORCELSKI, C.; PELISSARI, G.; HANUS, A. D.; ROSA, G. M. Demanda hídrica das culturas de interesse agronômico. Enciclopédia biosfera, v. 9, n.17, p. 969, 2013.

CASTANHEIRA, E.G.; GRISOLI, R.; COELHO, S.; SILVA, G.A.; FREIRE, F. Life-cycle assessment of soybean-based biodiesel in Europe: comparing grain, oil and biodiesel import from Brazil. Journal of Cleaner Production, v.102, p.188-201, 2015.

https://doi.org/10.1016/j.jclepro.2015.04.036

CLAESSEN, M. E. C. (Org.). Manual de métodos de análise de solo. 2. ed. rev. atual. Rio de Janeiro: EMBRAPA-CNPS, 1997. 212 p. (EMBRAPA-CNPS. Documentos, 1).

CONAB. Acompanhamento da safra brasileira de grãos - 9o Levantamento de Safra 2017/18. v. 5, junho de 2018. Disponível em: https://www.conab.gov.br/info-

agro/safras/graos. Acesso em: 15 jun. 2018.

COSTA, N. R.; ANDREOTTI, M.; LOPES, K. S. M.; YOKOBATAKE, K. L.; FERREIRA, J. P.; PARIZ, C. M.; BONINI, C. S. B.; LONGHINI, V. Z. Atributos do solo e acúmulo de carbono na integração lavoura-pecuária em sistema plantio direto. Revista Brasileira de Ciência do Solo, v. 39, n. 3, p.852-863,

2015. http://dx.doi.org/10.1590/01000683rbcs2014026 9.

FERREIRA, D. F. Sisvar: a guide for its bootstrap procedures in multiple comparisons. Ciência e Agrotecnologia [online]., v.38, n.2 p.109112, $2014 . \quad$ http://dx.doi.org/10.1590/S141370542014000200001.

FIETZ, R. C.; COMUNELLO, E.; FLUMIGNAN D. L.; Deficiência hídrica na região de Dourados, MS. In: CONGRESSO BRASILEIRO DE ENGENHARIA AGRÍCOLA, 42., 2013, Fortaleza. Anais [...]. Fortaleza: SBEA, 2013. 1 CD-ROM; CONBEA 2013.

FREIRE FILHO, F. R.; RIBEIRO, V. Q.; BARRETO, P. D.; SANTOS, A. A. Melhoramento genético. In: FREIRE FILHO, LIMA, J. A. de A.; RIBEIRO, V. Q. (Eds.). Feijão-caupi: avanços tecnológicos. 
Brasília: Embrapa Informação Tecnológica, 2005. p. 29-92.

GAVA, R.; FRIZZONE, J. A.; SNYDER, R. L.; JOSE, J, V.; FRAGA JUNIOR, E. F.; PERBONI, A. Estresse hídrico em diferentes fases da cultura da soja. Revista Brasileira de Agricultura Irrigada, v. 9, n. 6, p.349-359, 2015. http://dx.doi.org/ 10.7127/rbai.v9n600368.

HENCHION, M.; MCCARTHY, M.; RESCONI, V.C.; TROY, D. Meat consumption: trends and quality matter. Meat Science, v.98, p.561-568, 2014. https://doi.org/10.1016/j.meatsci.2014.06.007

HUNGRIA, M. Co-inoculation of soybeans and common beans with rhizobia and azospirilla: strategies to improve sustainability. Biology Fertility Soils, v.49, p.791-801, 2013. http://dx.doi.org/10.1007/s00374-012-0771-5.

HUNGRIA, M.; NOGUEIRA, M.A.; ARAUJO, R.S. Soybean Seed Co-Inoculation with Bradyrhizobium spp. and Azospirillum brasilense: A New Biotechnological Tool to Improve Yield and Sustainability. American Journal of Plant Sciences, v.6, p.811-817, 2015. http://dx.doi.org/10.4236/ajps.2015.66087

JENKINSON, D. S.; POWLSON, D. S. The effects of biocidal treatments on metabolism in soil. V. A method for measuring soil biomass. Soil Biology \& Biochemistry, v.8, n.3, p.209-213, 1976. https://doi.org/10.1016/0038-0717(76)90005-5

KASCHUCK, G.; ALBERTON, O.; HUNGRIA, M. Quantifying effects of different agricultural land uses on soil microbial biomass and activity in Brazilian biomes: inferences to improve soil quality. Plant Soil, v.338 p.467-481, 2011. http://dx.doi.org/10.1007/s11104-010-0559-z.

LEITE, L.F.C.; ARRUDA, F.P.; COSTA, C.N.; FERREIRA, J.S.; HOLANDA, M.R.N. Qualidade química do solo e dinâmica de carbono sob monocultivo e consórcio de macaúba e pastagem. Revista Brasileira de Engenharia Agrícola e Ambiental, v.17, p.1257-1263, 2013. https://doi.org/10.1590/S1415-

43662013001200002

LOPES, A.A.C.; SOUSA, D.M.G.; CHAER, G.M.; REIS JÚNIOR, F.B.; GOEDERT, W.J.; MENDES, I.C. Interpretation of microbial soil indicators as a function of crop yield and organic carbon. Soil
Science Society of America Journal, v. 77, n. 2, p.461-472, 2013. http://dx.doi.org/10.2136/sssaj2012.0191.

LOPES, C. A. A; SOUSA, M. G. D.; REIS JR, B. F.; FIGUEIREDO, C. C.; MALAQUIAS, V. J.; SOUZA, M. L.; MENDES, C. I. Temporal variation and critical limits of microbial indicators in oxisols in the Cerrado, Brazil. Geoderma regional, v.12, p. 7282 ,

2018.

https://doi.org/10.1016/i.geodrs.2018.01.003.

LOURENTE, E. R. P.; MERCANTE, F. M.; ALOVISI, A. M. T.; GOMES, C. F.; GASPARINI, A. S.; NUNES, C. $M$. Atributos microbiológicos, químicos e físicos de solo sob diferentes sistemas de manejo e condições de cerrado. Pesquisa Agropecuária Tropical, v.41, n.1, p.20-28, 2011. https://doi.org/10.5216/pat.v41i1.8459

MAZZUCHELLI, E. H.; MIGNACCA, F. A.; ARAÚJO, F. F.; REBONATTI, M. D.; TIRITAN, C. S. A atividade microbiológica do solo é influenciada pela rotação de culturas? Colloquium Agrariae, v. 13, n.(esp.), p.01-07, 2017. https://doi.org/10.5747/ca.2017.v13.nesp.00016 $\underline{3 .}$

MERCANTE, F. M. Os micro-organismos do solo e a dinâmica da matéria orgânica em sistema de produção de grãos e pastagem. Dourados: Embrapa Agropecuária Oeste, 2001. (Sistema plantio direto, 5).

NAVROSKI, D.; MOREIRA, A.; GUIMARÃES, F. M.; COLOZZI FILHO, A. Changes in microbiological attributes of a Red Latosol under different cropping systems. Semina: Ciências Agrárias, v.39, n.3, p.971-982, 2018. https://doi.org/10.5433/1679$0359.2018 v 39 n 3 p 971$.

OLIVEIRA, P.; NASCENTE, A. S.; KLUTHCOUSKI, J. Soybean growth and yield under cover crops. Revista Ceres, v.60, n.2, p.249-256, 2013. http://dx.doi.org/10.1590/S0034737X2013000200014.

REIS JUNIOR, F.B.; MENDES, I.C. Biomassa microbiana do solo. Planaltina: Empresa Brasileira de Pesquisa Agropecuária; 2007. 40 p. (Documentos, 205) 
SAMPAIO, D. B.; ARAÚJO, A. S. F.; SANTOS, V. B. Avaliação de indicadores biológicos de qualidade do solo sob sistemas de cultivo convencional e orgânico de frutas. Ciência e Agrotecnologia, v.32, n.2, p.353-359, 2008. https://doi.org/10.1590/S1413-

70542008000200001

SANTOS, H.P.; FONTANELI, R.S.; SPERA, S.T.; DREON, G. Fertilidade, teor de matéria orgânica do solo em sistemas de produção com integração lavoura, pecuária sob plantio direto. Revista Brasileira de Ciências Agrárias, v.6, p.474-482, 2011. https://doi.org/10.5039/agraria.v6i3a1266

SANTOS, H. G.; JACOMINE, P. K. T.; ANJOS, L. H. C.; OLIVEIRA, V. A.; LUMBRERAS, J. F.; COELHO, M. R.; ALMEIDA, J. A.; CUNHA, T. J. F.; OLIVEIRA, J. B. Sistema brasileiro de classificação de solos. 3 . ed. Brasília: Embrapa, 2013. 353p.

SOARES, D. S. Biomassa vegetal e atributos do solo em diferentes sistemas de produção sob plantio direto no cerrado. 2017. 97f. Dissertação (Mestrado) - Faculdade de Agronomia e Medicina Veterinária da UNB, Brasília, 2017.

TABATABAI, M.A.; BREMNER, J.M. Use of $p$ nitrophenyl phosphate for assay of soil phosphatase activity. Soil Biology and Biochemistry, v.1, p.301-307, 1969. https://doi.org/10.1016/0038-0717(69)90012-1

VANCE, E. D.; BROOKS, P. C.; JENKINSON, D. S. An extraction method for measuring soil microbial biomass C. Soil Biology \& Biochemistry, v. 19, n.6, p.703-707, 1987. https://doi.org/10.1016/0038-0717(87)90052-6 